\title{
The IMPACT OF PERSONNEL COSTS ON THE COMPETITIVENESS OF AUTOMATED MANUFACTURING SYSTEMS
}

\author{
Konstantin Novikov \& Jana Kleinova
}
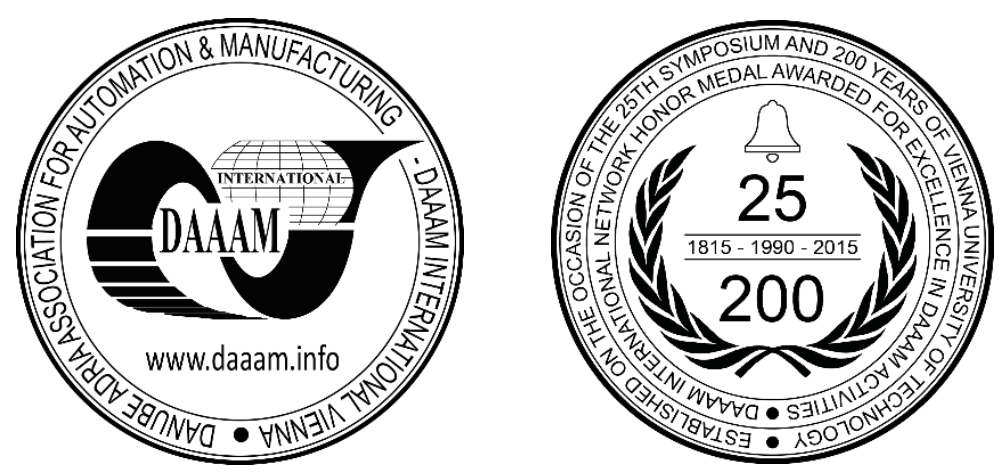

This Publication has to be referred as: Novikov, K[onstantin] \& Kleinova, J[ana] (2018). The Impact of Personnel Costs on the Competitiveness of Automated Manufacturing Systems, Proceedings of the 29th DAAAM International Symposium, pp.0916-0921, B. Katalinic (Ed.), Published by DAAAM International, ISBN 978-3-902734-20-4, ISSN 1726-9679, Vienna, Austria

DOI: $10.2507 / 29$ th.daaam.proceedings. 132

\begin{abstract}
This article focuses on the competitiveness of industrial companies. It follows up on the Fourth Industrial Revolution, which has dramatically changed the trends in the field of production. Its aim is a cost evaluation of automated manufacturing systems, mainly considering the impact of personnel costs on costs of production. Calculation is performed on a full cost basis. Also, the paper includes a case study, which demonstrates the difference in personnel costs between two identical production units located in different countries. The outcome aims to either prove or disprove the assumption that the personnel costs of automated production systems do not have a significant impact on production costs.
\end{abstract}

Keywords: Industry 4.0; automation; costs; competitiveness

\section{Introduction}

Due to the increasing competition in markets generally, all industrial companies have to deal with the issue of cost reduction. The success or failure of a company is caused not only by the price and the quality, but by the cost of the product as well. Achieving higher profits and better standing of the company depends on the ability to reach the same quality of production with lower cost than the competitors at the same time. [1]

Companies exporting abroad are largely dependent on the monetary policy of the state in which production is located. This affects the level of profits being made and also the competitiveness of the company. Based on these difficulties, we witness companies moving their production to 'cost-friendly' countries, which might include lower than average wages as well as costs related to logistics and energy.

The tax policy of each state also determines the production location. The Industry 4.0 concept may be regarded as a solution which partially eliminates political, economic and social impacts. 


\subsection{Industry 4.0}

Digitization and automation of production is part of the Fourth Industrial Revolution. 'Smart factories' are a logical step towards keeping manufacturing plants in developed countries competitive and avoid moving their work to emerging markets. Specialized literature dealing with Industry 4.0 assumes the gradual displacement of workers' professions. These will be replaced by automated systems that partially need operating staff.

The cost of direct wages in production will be reduced due to a significant drop off in the number of workers directly involved in the production process. The production units will have only a few support staff, which, depending on available resources, will lead to an increase in the share of machinery costs but also to increased production efficiency. As a result, personnel costs will be reduced and their percentage in the production costs of the product minimized. On the other hand, there may be a certain increase of employees in pre-production stages. [8]

\subsection{The impact of personnel costs}

Personnel costs include not only direct wages but the cost of indirect wages as well. The reduction in the number of manufacturing workers significantly reduces direct wages and therefore personnel costs. However, the question remains whether a lower number of production workers will decrease the importance of personnel costs in so far as their impact on the final product is as small as the removal of production to another country with a cheaper labour force would not be economical.

The purpose of this paper is to disprove the assumption that the personnel costs of automated production systems do not have a significant impact on production costs. The outcome aims to demonstrate the impact of personnel costs using a comparison of cost evaluation of two identical production units located in different countries. It should be noted that there are some limitations of this research. The area of interest of the study is only for less repetitive production, as the proportion of personnel costs in highly repetitive production could vary considerably.

\section{Methodology}

In order to make cost calculations, the complexity of individual products must be known. This can be determined by measuring labour consumption. However, for a comprehensive understanding of the manufacturing process, material flows are first defined and all workplaces are analysed. [6] By standardizing the work and finding out all the annual production costs, it is later possible to determine the cost of any type of product that is produced in the given segment.

Full cost-based calculations are used to determine the production costs. The objective is to capture all costs incurred during the manufacturing process. The methodology of calculation is based on the literature [2] and [7], where the computational relationship of the production cost is described as:

$$
P C=D M a+D W a+I M a+M C+T C+C \text { ntech }
$$

$\begin{array}{lll}P C & \ldots \text {. production costs } & {[\mathrm{EUR}]} \\ D M a & \ldots \text { direct material } & {[\mathrm{EUR}]} \\ D W a & \ldots \text { direct wages } & {[\mathrm{EUR}]} \\ I W a & \ldots \text {. indirect wages } & {[\mathrm{EUR}]} \\ I M a & \ldots \text {. indirect material costs } & {[\mathrm{EUR}]} \\ M C & \ldots \text { machinery costs } & {[\mathrm{EUR}]} \\ T C & \ldots \text { tool costs } & {[\mathrm{EUR}]} \\ C_{n t e c h} & \ldots \text {..non- technological costs } & {[\mathrm{EUR}]}\end{array}$

In this case, the calculation unit is considered to be a product that has defined required work performance. Material consumed for the production of a calculation unit is called 'direct material' and is determined using a bill of material based on the material consumption standards. Direct material does not change due to the migration of the production unit and can be used as a constant. The difference between the production costs and direct material is called 'processing costs'. [5]

$$
\operatorname{Pr} C=P C-D M a
$$

After the cost breakdown into technological and non-technological operations, processing costs are specified as follows: 


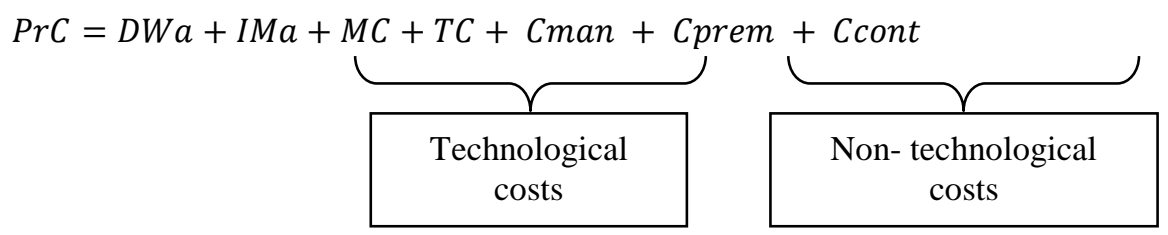

$\operatorname{PrC} \quad$...processing costs

$C_{\text {tech. }}$...technological costs

$C_{n t e c h}$...non- technological costs

$C_{\text {man }}$...manipulation costs

$C_{\text {prem }}$...premises costs

$C_{\text {cont }}$...control costs
[EUR]

[EUR]

[EUR]

[EUR]

[EUR]

[EUR]

\section{Case study}

The case study compares the costs of an original production unit in Switzerland (Company $\mathrm{CH}$ ) and a new production unit in the Czech Republic (Company CZ). These production units are identical, they are engaged in the fabrication of heating elements, and their machinery is not debited. First, the processing costs of the production units were compared.

The following is a comparison of the annual technological costs of both units, which do not include manipulation, premises or repairs. Calculations of the processing costs and the production costs of representative products will be made to demonstrate the impact of the cost change after the relocation of production.

All financial data are listed in monetary units (MU), which are recalculated using the key (but the ratios will be true).

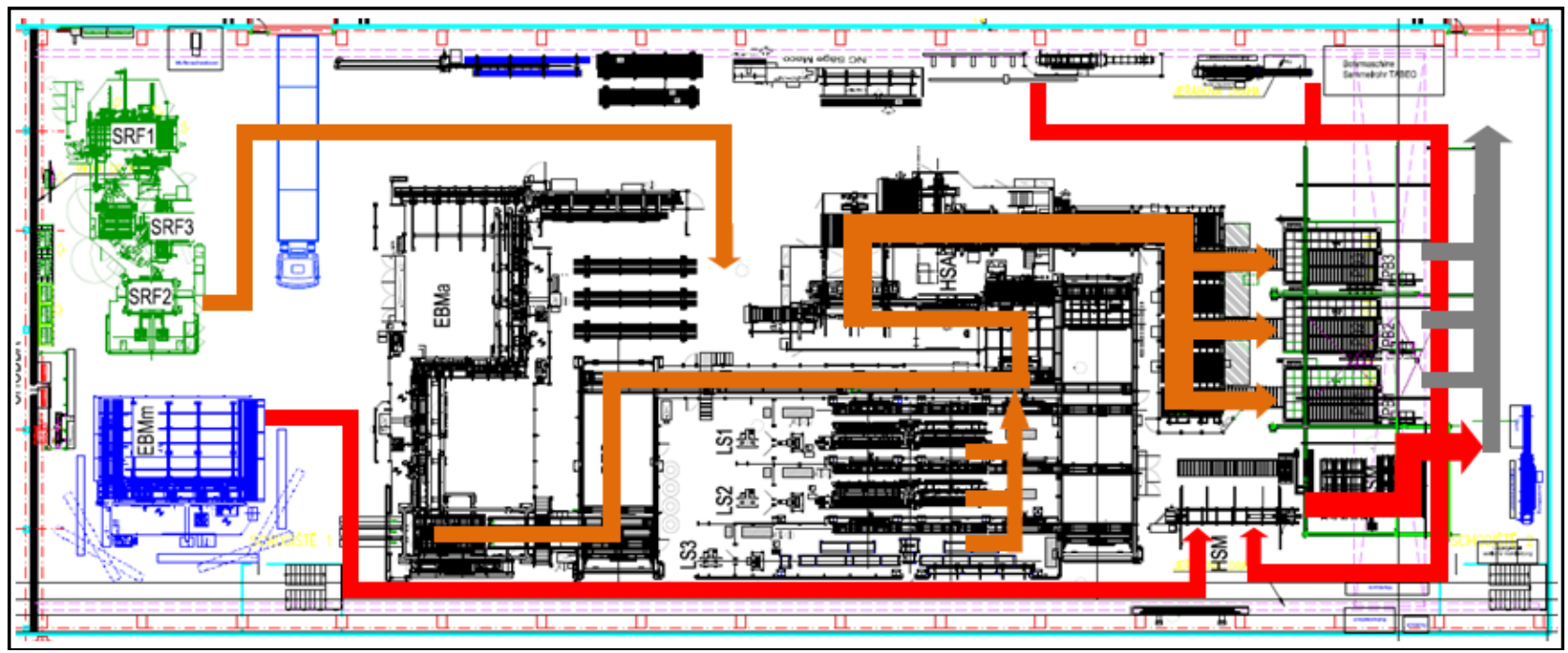

Fig. 1. Material flow [4]

Fig. 1 outlines material flow in the production unit layout. The material flow did not change after the relocation of production. Brown lines indicate the flow of the main commodity. Red lines represent the flow of the auxiliary material. Grey shows the final handling and transport from the workshop.

\subsection{Annual cost of production units}

Comparison of annual processing costs can be used as one of the benchmarks for cost evaluation of the production units. These costs result from production costs but do not include direct material cost.

The assumption is that the supplier of direct material will not change (after relocation) and processing costs will stay the same for both production units. 


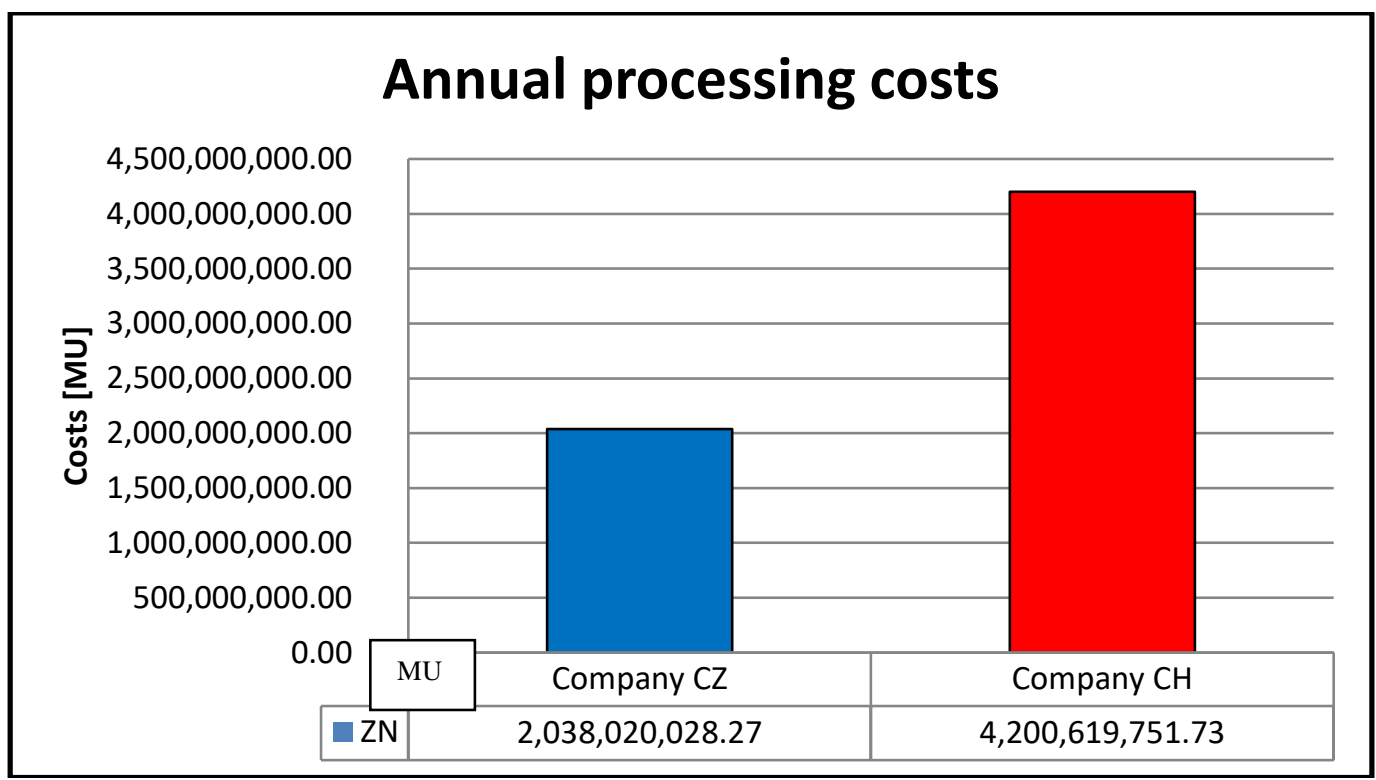

Fig. 2. Annual processing costs

It can be deduced from Fig. 2 that Company $\mathrm{CH}$ has an increase of $2162599723 \mathrm{MU}$ in annual processing costs, which is more than twice as expensive as Company CZ. The most significant impact on the change in processing costs change is hidden in the technological costs. Annual technological costs, which are (together with non-technological costs) part of the processing costs, have to be compared in order to detect the major differences in processing costs.

\begin{tabular}{|c|c|c|c|}
\hline \multicolumn{2}{|c|}{$\begin{array}{c}\text { Technological costs [MU]- } \\
\text { Company } \mathrm{CH}\end{array}$} & \multicolumn{2}{|c|}{$\begin{array}{c}\text { Technological costs [MU]- } \\
\text { Company CZ }\end{array}$} \\
\hline DWa & 1319299369,42 & DWa & 320104001,00 \\
\hline IMa & 221667300,00 & IMa & 221667300,00 \\
\hline $\mathrm{MC}$ & 859013535,24 & $\mathrm{MC}$ & 859013535,24 \\
\hline $\mathrm{TC}$ & 49259400,00 & $\mathrm{TC}$ & 49259400,00 \\
\hline Manipulation & 207246917,50 & Manipulation & 104338103,29 \\
\hline Premises & 913809159,02 & Premises & 228452289,76 \\
\hline Control & 126065175,00 & Control & 126065175,00 \\
\hline IWa & 293177637,65 & IWa & 84237895,00 \\
\hline SUM & 3989538493,83 & SUM & $\begin{array}{l}11 \\
1\end{array}$ \\
\hline
\end{tabular}

Table 1. Technological costs

Table 1 represents the greatest deviations in technological costs of both units which occur in direct and indirect wages. The difference of annual direct wages is 999195368 MU. Another significant factor is the cost of premises which is $685356870 \mathrm{MU}$ higher in Company $\mathrm{CH}$. There are also some variations in energy costs, where Company CZ has 102908814 MU less.

\subsection{Product costs}

Although deviations in annual processing costs of both production units are known, it is still essential to ascertain the impact of these costs on particular products. Therefore, a commonly produced representative product is selected.

Processing costs are assigned to the representative product by a step-by-step calculation. [3] It accurately copies the material flow of the product through the cost locations. Cost locations are expressed by the hourly rate of these places and all selected products passing through them have a determined time consumption for each cost location. 


\section{Processing costs of product}

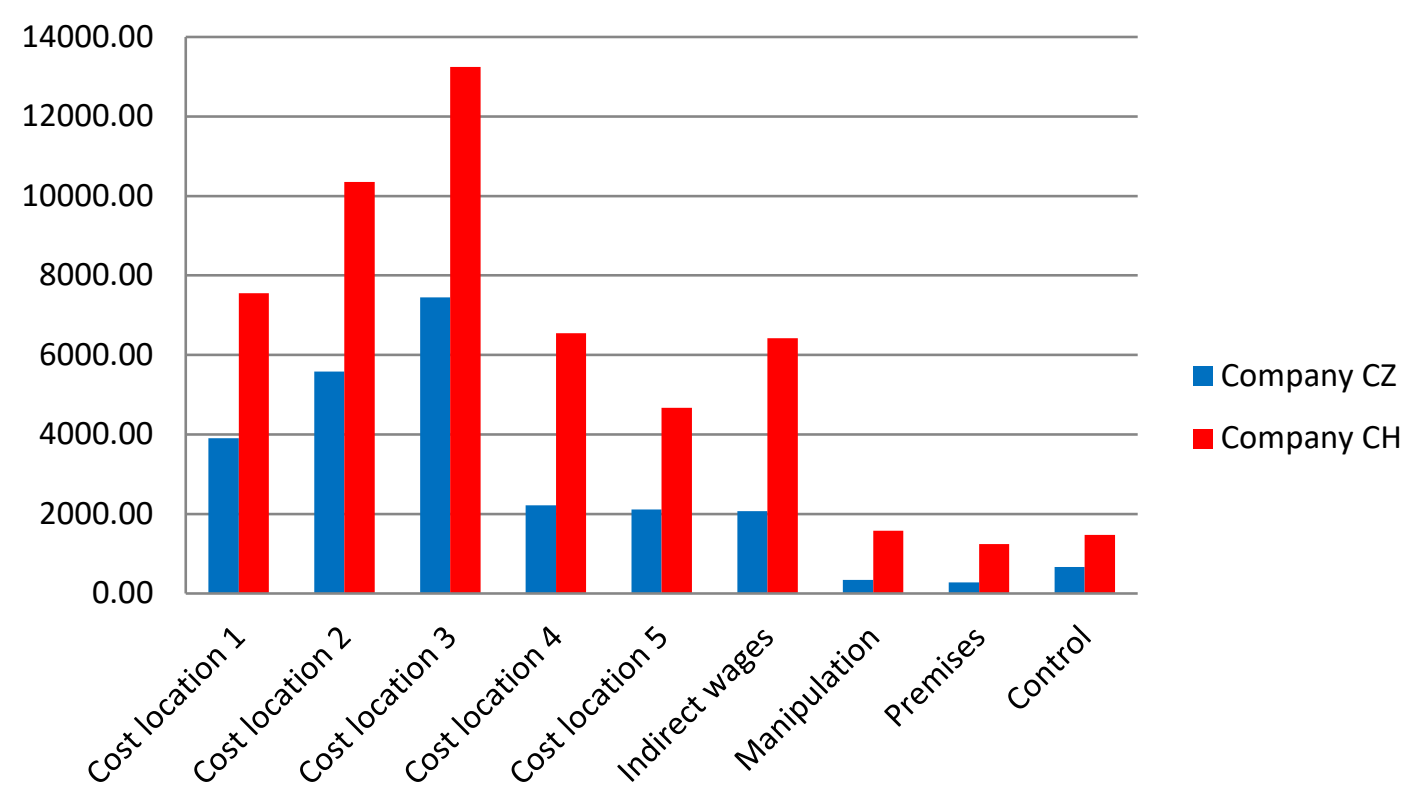

Fig. 3. Product processing costs

Processing costs of this product are equal to $24635 \mathrm{MU}$ in Company CZ and $53077 \mathrm{MU}$ in Company CH. All types of costs are higher for the Swiss company, mainly due to personnel costs, which were reflected in the cost locations by means of an hourly rate. In order to determine the price of products, production costs are used as the basis of calculation, to which the administrative and sales charges, profit and eventually rebate, are added. It is necessary to determine the cost of direct materials to compare the production costs of common pieces. Direct material, together with processing costs, makes up the production costs.

\section{Production costs of product}

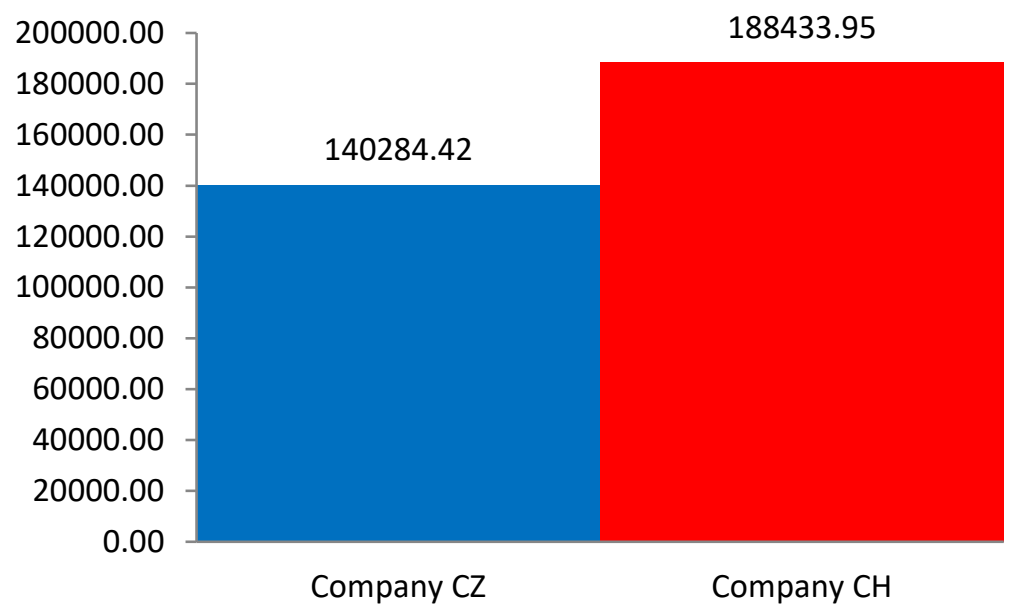

Fig. 4. Product production costs

Company $\mathrm{CH}$ production costs are $48150 \mathrm{MU}$ higher, which is $34 \%$ more than in Company CZ. Although administrative or sales overheads are not included in the calculation, we can assume that if the final price of products after the relocation of production has not changed, there is an increase in profit.

\section{Conclusion}

The purpose of this article was to rebut the assumption that personnel costs do not have a significant effect on the level of production costs in automated production systems. Full cost based calculation was used for the evaluation. Determining and comparing processing costs has made it possible to assess how much personnel costs are involved. The calculation of production costs confirmed that direct and indirect wages form a significant component of costs. 
The annual processing costs in Company $\mathrm{CH}$ are approximately twice that of Company CZ. The result of the case study thus disproves the assumptions about the non-significant importance of personnel costs. This study also demonstrates the impact of a cheaper workforce on competitiveness. Production costs of representative products of both production units vary considerably because of personnel costs (as shown on Fig. 4), even with the small number of workers directly involved in the production process. It is necessary to realize that increasing automation will cause a shift from personnel costs to machine costs. It will then be appropriate to look at the costs in light of the increase in machinery costs and decreasing personnel costs.

Next step will be a comparison of the results of this study with the level of personnel costs for mass production. It would be interesting to ascertain whether, even with a larger number of manufactured products, the share of wage costs remains a non-negligible item.

\section{Acknowledgments}

This article was created with the support of the internal grant of the University of West Bohemia, SGS-2018-031entitled Optimizing sustainable production system parameters.

\section{References}

[1] Šrajer, V., Kleinová, J. (2011). Effective manufacturing layout as a condition of economy of production. In Annals of DAAAM for 2011 \&Proceedings of The 22nd International DAAAM Symposium "Intelligent Manufacturing \& Automation: Power of Knowledge and Creativity". Vienna: DAAAM International Vienna, TU Wien. s. 525-526. ISBN: 978-3-901509-83-4 , ISSN: 1726-9679

[2] Ofert, K. (2006). Kostenrechnung, Kiehl, ISBN 3-470-51-102-0

[3] Dhillon, B.S. (2010). Life Cycle Costing for Engineers, CRC Press, ISBN 978-1-4398-1688-2

[4] Novikov, Konstantin. (2017). Cost evaluation of heating elements production . Diploma thesis (Ing.). Plzeň : Západočeská univerzita v Plzni, Fakulta strojní

[5] Šrajer, Vladimír. (2014). The arrangement of the production system with regard to the technological-design of a product. Disertační práce (Ph.D.). Plzeň : Západočeská univerzita v Plzni, Fakulta strojní

[6] Lambert, Douglas, Stock, Ellram, Lisa M. (2005). Fundamentals of logistics management. Vyd.2. Brno : CP Books. ISBN 80-251-0504-0

[7] Ehrlenspiel,K., Kiewert,A., Lindemann,U. (2007). KostengünstigEntwickelnundKonstruieren, Springer, ISBN 978-3-540-74222-7

[8] Ustundag, Alp. (2017). Industry 4.0 Managing The Digital Transformation. Springer. ISBN 9783319578699. 